\title{
LA PEDAGOGIA DE ROUSSEAU: plan de lecciones *
}

\author{
Émile Durkheim
}

\section{PRIMERA LECCION}

\section{A) CARACTER IDEAL Y ABSTRACTO DEL METODO}

1. El método de El contrato. Se trataba de elaborar un plan de la sociedad que conviniera al hombre en general; en consecuencia, un plan fundado en la naturaleza del hombre. Además, el problema fundamental consistía en reencontrar los elementos esenciales del hombre.

II. El problema de la educación es expuesto por Rousseau en los mismos términos. No se pregunta cuál es la educación conveniente para tal país y en tal tiempo. Estas son modalidades accidentales que no van al fondo de las cosas y de la cuales es necesario hacer abstracción.

TEXTO 1: Carácter ideal y abstracto de la pedagogía dc Rousseau.

"En toda clase de proyecto hay que considerar dos cosas: primeramente, la bondad absoluta del proyecto; en segundo lugar, la facilidad de la ejecución. Respecto al primer extremo, es suficiente, para que el proyecto sea admisible y practicable en sí mismo, que cuanto tenga de bueno esté en la naturaleza de la cosa; aquí, por ejemplo, que, la educación propuesta sea conveniente al hombre, y bien adaptada al corazón humano. La segunda conside ${ }^{*}$ ración depende de las relaciones dadas en determinadas situaciones: relaciones accidentales a la cosa, las cuales como consecuencia, no son necesarias y pueden variar al infinito. De esta forma, tal educación puede ser practicable en Suiza y no serlo en Francia...

Ahora bien, todas estas aplicaciones particulares, no siendo esenciales a mí tema, no entran en mi plan".(Emilio, "Prefacio", p. 33)

TEXTO 1 bis: Carácter ideal de la pedagogía.

(Leer el pasaje sobre la movilidad de las cosas humanas que sigue a la cita)

"Esto, pues, hace generalizar nuestros puntos de vista y considerar en nuestro discípulo el hombre abstracto, el que está expuesto a todas las eventualidades de la vida humana". (Emilio 1, p. 72)

\footnotetext{
${ }^{*}$ Publicado por primera vez en la Revue de metaphysique et de morale, No. 26, 1919, pp. 153-180.

** Las citas del "Prefacio" han sido tomados de la traducción del Emilio de Luis Aguirre Prado (Madrid: Biblioteca EDAF, 1985). Los demás textos han sido extractados de la edición del Emilio de la Editorial Bruguera (Barcelona: 1983), a cargo de A. Cardona de Gilbert y A. González Callego, en versión castellana de F. L. Cardona. En esta edición, la más popular y accesible, no se incluyó el "Prefacio". La ordenación romana que sigue a Emilio, indica el número del libro en el cual se encuentra el texto citado.
} 
Es pues un hombre al que se trata de formar.

TEXTO 2: Se trata de formar un hombre.

"En el orden natural, los hombres son todos iguales; luego, su vocación común es el estado del hombre, y quien hubiere sido bien criado para éste, no puede desempeñar mal los que con él se relacionan. Que destine mí discípulo a la espada, a la iglesia o a la abogacía, poco me importa. El oficio que quiero enseñarle es e! vivir.

Cuando salga de mis manos, yo estoy de acuerdo, en que no será ni magistrado, ni soldado, ni sacerdote; primeramente será hombre, todo cuanto debe ser un hombre y sepa serlo, si fuera necesario, también como el que más, y aunque la fortuna quiere hacerle cambiar de situación, él siempre se encontrará en la misma...

Nuestro verdadero estudio es el de la condición humana". (Emilio 1, p. 71)

Siempre la misma necesidad de descartar lo accidental, lo variable y de encontrar lo esencial, la roca sobre la cual reposa la realidad humana.

\section{B) EL OPTIMISMO PEDAGOGICO DE ROUSSEAU}

1. Según textos bien conocidos, el niño sería naturalmente bueno. Todo cuanto viene del hombre es malo.

\section{TEXTO 3: Bondad nativa.}

"Todo es perfecto cuando sale de las manos de Dios, pero todo degenera en las manos del hombre. Obliga a una tierra a que dé lo que debe producir otra, a que un árbol dé un fruto distinto...lo turba y desfigura todo; ama la deformidad, lo monstruoso; no quiere nada tal como ha salido de la naturaleza, ni al mismo hombre". (Emilio 1, p. 65)

\section{¿Es decir que nada le faltaría por hacer?}

“...De otra forma" [si no se encaminara al hombre, si no se rodeara su naturaleza] "todo sería peor, ya que nuestra especie no quiere ser formada a medias. En el estado en que están las cosas, un hombre abandonado desde su nacimiento así mismo sería el más desfigurado de los mortales; las preocupaciones, la autoridad, la necesidad, el ejemplo, todas las instituciones sociales, en las que estamos sumergidos, apagarían en él su natural modo de ser y no pondrían nada en su lugar que los sustituyese". (Emilio 1 p.65)

Consecuencia pedagógica. Dejar hacer. El niño tiene la moralidad intrínseca.

El hombre debe entonces mantenerse a distancia del niño. El juicio de aquel es naturalmente justo. No lo deformemos,

Desde este punto de vista, toda la discusión descansará sobre la cuestión de saber si el niño es perfecto; si no tiene vicios naturales, etc. Esta es la tesis corriente prestada de Rousseau.

II. Pero el texto que sigue deberá hacernos reflexionar. 
TEXTO 4: Educación. Su poder:

"Nacemos débiles, necesitamos ser fuertes, y al nacer carecemos de todo y se nos debe proteger; nacemos torpes y nos es esencial conseguir la inteligencia. Todo esto de que carecemos al nacer, tan imprescindible en la adolescencia, se nos ha dado por medio de la educación". (EmiLio 1, p. 66)

Necesidad de limitar la naturaleza. Rousseau encuentra que todo es perfecto en ella.

III. Si este fuera el pensamiento que tomamos prestado de Rousseau, la educación debería estar reducida al mínimo. Se debería dejar hacer. Ahora bien, nadie tiene un sentimiento más vivo del poder y de la necesidad de la educación que Rousseau. La educación transforma la naturaleza, la corrompe.

TEXTO 5: La desnaturalización.

"El hombre de la naturaleza lo es todo para sí; él es la unidad numérica, el entero absoluto, que no tiene más relación que consigo mismo o con su semejante. El hombre civilizado es una unidad fraccionaria que determina el denominador y cuyo valor expresa su relación con el entero, que es el cuerpo social.

Las buenas instituciones sociales son aquellas que poseen el medio de desnaturalizar al hombre, quitarle su existencia absoluta para reemplazarla por otra relativa, y transportar el yo dentro de la unidad común; de tal manera que cada particular no se crea un entero, sino parte de la unidad, y sea sensible solamente en el todo". (Emilio 1, pp. 68-69, ver los ejemplos)

¿Por qué? Primero: debilidad del niño. Equilibrio de los deseos y de las fuerzas. No existen en el niño.

Debilidad necesaria (ver pp.104-7IO5).

TEXTO 5 bis: Debilidad de la infancia. Sus razones.

Si el hombre naciera grande y fuerte, su talla y su fuerza le serian inútiles hasta que aprendiera a servirse de ellas y, luego, abandonado así mismo, se moriría de miseria antes de que los demás comprendiesen sus necesidades". (Emilio, 1, p. 66)

Segundo: contradicción del hombre natural y del hombre civil. Desnaturalización necesaria.

IV. El educador persigue entonces un fin positivo: colocar al niño en armonía con su medio.

TEXTO 6 : El ideal:

"¿En qué consiste, pues, la sabiduría o la ruta de la verdadera felicidad? Precisamente no está en disminuir nuestros deseos, ya que si estuvieran por debajo de nuestro poder, una parte de nuestras facultades quedaría ociosa, y nosotros no gozaríamos de todo nuestro ser. Esto no consiste en otra cosa que extender nuestras facultades, pues si nuestros deseos se extendieran al mismo tiempo en mayor 
cantidad, seríamos más infelices. Pero esto es disminuir el exceso de los deseos sobre las facultades y poner en perfecta igualdad el poder y la voluntad. Solamente entonces es cuando todas las fuerzas están en actividad; el ánimo, sin embargo, permanecerá tranquilo, y el hombre disfrutará de un justo equilibrio.

Es así como la naturaleza a primera vista lo ha constituido, ya que ella lo ha hecho todo de la mejor manera ... Es en este estado primitivo cuando el equilibrio del poder y del deseo se encuentran y cuando el hombre deja de ser desgraciado". (Emilio 1, pp. 123-124)

TEXTO 7: Desnaturalización. Produciendo la armonía entre nosotros.

"Aquel que, en el orden civil, quiere conservar la primacía de los sentimientos naturales, no sabe lo que quiere. Siempre en contradicción consigo y fluctuando entre sus propensiones y sus deberes, no será jamás ni hombre ni ciudadano, ni será bueno para él ni para los demás. Será uno de los hombres actuales, un francés, un inglés, un burgués; no será nada". (Emilio 1, p.69)

TEXTO 8 : No imitar.

"Los padres que viven en el estado civil, y llevan a este estado a su hijo antes de la edad necesaria". (Emilio 11, p. 129)

Formar al hombre social

\section{C) POR QUÉ ES NECESARIO TOMAR LA NATURALEZA POR GUIA}

I. En esta acción, se debe tomar la naturaleza como modelo, como guía.

II. ¿Por qué? El niño es el hombre en el estado natural. Antes de la sociedad. Ahora bien, el estado natural es un estado de perfección. No el estado de perfección absoluta sino su género. Es en cierto sentido entonces un modelo.

Pongamos por máxima incontestable que los primeros movimientos de la naturaleza son siempre rectos; no hay perversidad original en el corazón humano" (Emilio II, p. 140). Explicación. Imperfecciones, ¿de dónde? Deseos no apropiados a la naturaleza; ¿de dónde podrían venir?

Pero no hay una bondad original en sentido positivo.

III. He aquí por qué la naturaleza del niño debe ser respetada. ¿Es perfecta? No. Se trata de criar un niño. ¿Cómo? Conforme a su naturaleza tal como ella es al estado de pureza.

¿Y esto es todo? ¿Es este el ideal? No. Rousseau solamente dice que puesto que es un niño hay que criarlo como tal, siguiendo su naturaleza infantil. Condición natural del hombre al nacer. Es así porque es su naturaleza. "La naturaleza quiere que los niños sean niños antes de ser hombres" (Emilio II, p. 137). "La humanidad tiene su puesto en el orden de las cosas; la infancia posee también el suyo en el orden de la vida humana" (Emilio, II, p. 123). Ver página 31 del "Prefacio". 
TEXTO 9 : Buscar el niño en el niño.

"Los más sabios ... buscan siempre al hombre en el niño, sin pensar en lo que es éste antes de ser hombre ... Comenzad, pues, por estudiar mejor a vuestros alumnos; pues hoy seguramente no los conocéis". (Emilio, "Prefacio", p. 32)

IV.Sin embargo, ¿por qué esta preferencia? No es sólo el ideal. ¿Por qué no el otro? La misma oposición. ¿Acaso la pregunta no está zanjada por adelantado?

De ningún modo. La conciliación es posible. Hemos visto cómo y por qué. El problema se plantea en los mismos términos para la educación. Dos educaciones. Naturaleza y hombre. Conciliación necesaria.

\section{TEXTO 10 : Desnaturalización. En qué debe consistir.}

"Si los dos fines que nos proponemos pudieran unificarse borrando las contradicciones del hombre, eliminaríamos un gran obstáculo para su felicidad. Faltaría, para juzgar de ello, ver al hombre del todo formado, observar sus inclinaciones, ver sus progresos y seguirle; en una palabra, sería indispensable conocer al hombre natural. Creo que se darán algunos pasos en esta investigación después de leer este escrito". (Emilio, 1, pp.70-7I)

¿Cómo es posible entonces? Una es estable, dada; la otra es móvil, depende de nosotros. La primera debe facilitar la norma. "Puesto que el concurso de las tres educaciones es necesario a su perfección, nosotros no podemos hacer nada que dirija a las otras dos" (Emilio 1, p. 67). "Por tanto lo deberíamos todo a estas disposiciones primitivas" (Emilio 1, p. 68).

V. Lo que hay en la base de esta doctrina. Idea de que la naturaleza física es la única cosa (?) $)^{7}$ todo el resto es variable, cambiante. No puede proporcionar el principio estable de la conducta. Educación esencial. Es todo el hombre.

VI. Importancia del principio. Alguna vez se dijo que la novedad de la pedagogía de Rousseau es su carácter psicológico. Es verdad. Estudio del niño. Mas carácter derivado, y derivado de un principio más general e importante.

¿Qué se requiere para que la pedagogía tenga un carácter científico? Que se apoye en una ciencia. Significado de ciencia: estudio objetivo de una realidad dada. Garantía aquí y allá contra las impresiones personales. Criterio objetivo.

Hasta el presente, la pedagogía carecía de esta condición. Traducía sentimientos, aspiraciones. Montaigne, Rabelais. Razones para ser considerados como argumentos. Que no hay nada que estudiar.

Rousseau, no hay que exagerar, parte de la pasión, de la influencia del medio. Sin embargo, emite la idea de que la educación, para ser normal, debe reproducir un modelo

\footnotetext{
${ }^{7}$ Palabra ilegible
} 
dado en la realidad. Además de elaboración, ya que alguna cosa hay por conocer. Hay que referirse a los hechos por encima de las fantasías.

Principio de la ciencia. Crítica de la idea de naturaleza. Demasiado a priori. Sin embargo, en principio, es un marco objetivo.

VII. Contragolpe psicológico. Psicología abstracta y artificial. No basta decirlo. Marcha de la naturaleza.

Principio de la Encyclopédie.

\section{SEGUNDA LECCION}

\section{A) ¿QUE ES LO QUE NOS ENSEÑA LA NATURALEZA SOBRE LA EDUCACION?}

1. Regreso al principio. Dos educaciones. Educación para la naturaleza. Educación para el hombre. La primera es el prototipo; ¿por qué? ¿Es simplemente imposible? Otra razón. Si esta educación no puede ser cambiada, es porque está fundamentada en la naturaleza de las cosas. Es entonces perfecta en su género. Se tiene así un modelo.

Importancia de este principio. El modelo no es arbitrarí3. Hay algo por conocer, por observar. Materia de una ciencia sobre la cual se apoye la pedagogía. Por consiguiente, la pedagogía se vuelve menos una Construcción exclusivamente subjetiva y sentimental.

II. ¿Qué es lo que nos enseña la naturaleza sobre la manera de criar? Ira. Regla. Nos enseña que existe un cierto número de necesidades fundamentales que para ser satisfechas no demandan más que el poderse desarrollar libremente. Espectáculo de una libre expansión de la actividad cuando es dejada por sí misma. El animal. Imitémosle. Dejemos hacer. La regla de la libertad es la base de todos los consejos del primer Libro. Nada de capillos. Nada de pañales.

TEXTO 1: No entorpecer los movimientos.

"Desde el momento en que el niño respira al salir de sus envoltorios, no admitáis que se le pongan otros que le vayan más estrechos o le opriman más. Nada de capillos, fajas ni pañales ... Cuando comience a fortalecerse, dejadle arrastrarse por la habitación; desarrollando y extendiendo sus tiernos miembros, nos daremos cuenta de cómo se van fortificando de día en día". (Emilio, 1, pp. 96-97)

Curación espontánea por la naturaleza. Nada de medicina.

TEXTO 2: Curación espontánea. Nada de medicina.

"A falta de saber curarse, el niño debe saber estar enfermo; este arte suple al otro, y con frecuencia resulta mucho mejor; es el arte de la naturaleza. Cuando el animal está enfermo, sufre en silencio y se tiende quieto; ahora bien, no es mayor nunca el número de animales lánguidos que el de hombres ... Se me contestará que los animales viven más conformes con la naturaleza y que están sometidos a menor número de males que nosotros. ¡Enhorabuena! Esta manera de vivir es precisamente la que voy a dar a 
mi alumno; por consiguiente, él debe sacar de ella el mismo provecho". (Emilio, 1, p. 90)

111. Pero ante esta regla, hay otra que bajo ciertas situaciones es la contraria. Llamado de El contrato. Para que el ciudadano sea natural, es necesario sentir una fuerza moral, por encima de él, comparable a las fuerzas físicas. Son necesarios, ineluctables, el límite y la contención.

El mismo sentimiento debe ser dado por la educación. El yugo de la necesidad.

TEXTO 3: El sentimiento de la necesidad.

"Que (el niño) sienta pronto sobre su cabeza altiva el duro yugo que la naturaleza impone al hombre, el pesado yugo de la necesidad, bajo el cual es necesario que todo ser se rinda; que vea esta necesidad en las cosas, pero nunca en el capricho de los hombres; que el freno que le retenga sea la fuerza y no la autoridad". (Emilio II, pp. 138-139)

TEXTO 4: Necesidad.

"Hombre! ...quédate en el sitio que te marcó la naturaleza en la cadena de los seres, y nada te podrá forzar a que salgas de él; no des coces contra el duro aguijón de la necesidad; y te agotes por resistir unas fuerzas que no te dispensó el cielo para ensanchar o prolongar tu existencia, sino para conservarla cómo y mientras él quisiese". (Emilio II, p. 128)

IV. ¿Por qué? El ideal de todo ser: adaptarse a su medio. Equilibrio entre las necesidades y los medios, entre las facultades y los deseos. Este es el verdadero poder, la verdadera fuerza, la verdadera condición de felicidad.

TEXTO 5: El ideal. Fuerzas.

'Cuando se dice que el hombre es débil, ¿qué es lo se pretende decir? La palabra debilidad indica una condición, una cualidad del ser al cual se aplica. Está donde la fuerza rebasa las necesidades; sea un insecto, o un gusano, es un ser fuerte, pero aquel en el cual las necesidades exceden a la fuerza, sea un elefante o un león, un conquistador o un héroe, y aunque sea un dios, éste es un ser débil ... El hombre es muy fuerte cuando está contento de ser lo que es, y es muy débil cuando quiere encumbrarse por encima de la humanidad". (Emilio ¡1, pp. 124-125)

TEXTO 6: El ideal.

"Un ser sensible en el cual las facultades fuesen iguales a los deseos sería un ser absolutamente feliz". (Emilio 11, p. 123)

¿Pero qué supone este equilibrio? Que el ser no se desarrolla sin término, que se detiene o es detenido. La idea de barrera, del límite infranqueable. "El mundo real tiene sus límites y el imaginario es infinito" (Emilio II, p. 124). Este equilibrio se realiza de forma natural en el animal. En toda la naturaleza. Está por lo tanto en el destino del hombre. Pero es más difícil de realizar debido a las facultades superfluas, virtuales. 
TEXTO 7: Facultades virtuales.

"Todos los animales tienen exactamente las facultades necesarias para conservarse. Solamente el hombre las tiene superfluas. ¿No es bien extraño que esta superfluidad sea el instrumento de su miseria?". (Emilio 11, p. 125)

TEXTO 8: Las facultades virtuales (ausencia de límite).

"[La naturaleza] ha puesto todas las otras [aquellas que no son necesarias actualmente] en el fondo de su alma [del hombre] como de reserva para desenvolverse a medida que las necesite ... Tan pronto como las facultades virtuales se ponen en acción, la imaginación, la más activa de todas, se despierta y las adelanta". (Emilio II, p. 124)

En el estado de naturaleza, ellas dormitan. Pero cualquier cosa las despierta y se extienden más allá de lo dado. Anticipan, desadaptan; y entonces no se siente más el límite, la barrera.

La imaginación.

TEXTO 8 bis:

"Es la imaginación lo que extiende por nosotros la medida dé las cosas posibles, tanto si es en bien como en mal, y por consiguiente excita y nutre los deseos con la esperanza de satisfacerlos. Mas el objeto que parecía a primera vista estar al alcance de la mano huye tan velozmente que no se le puede perseguir; cuando uno cree alcanzarlo, se transforma y se presenta a mucha distancia de nosotros. No viendo más el terreno ya recorrido, no lo contarnos por nada; el que nos falta recorrer se nos ha aumentado y se extiende sin cesar. Así uno se rinde sin llegar a su término, y cuanto más nos acercamos hacía el goce, más la felicidad se aleja de nosotros". (Emilio 11, p. 124)

V. ¿Qué resulta de esto? Nada no, satisface más; sólo sabemos inventar. Y después, ¿qué haremos sí somos limitados? El mundo no cede. De lo cual surge una dolorosa sensación de sorpresa.

TEXTO 9: Utilidad del sentimiento de resistencia.

"Acostumbrados a ver que todo cede ante ellos, ¡Qué sorpresa cuando, al Invadir el mundo, vean que todo se les resiste y se sientan aplastados por el peso de un universo que pensaban mover a su antojo! (Emilio II, p. 134).

(Ahora bien, por eso es necesario que estén al frente de las cosas).

VI. Además de la limitación, la resistencia implica sufrimiento. El sufrimiento está ante todo en la naturaleza.

TEXTO 10: El endurecimiento. Educación negativa. 
"Observad la naturaleza y seguid el camino trazado por ella. La naturaleza ejercita continuamente a los niños; endurece su temperamento con todo género de pruebas y les enseña muy pronto qué es pena y qué dolor ... Casi toda la primera edad es enfermedad y peligro". (Emilio 1, pp. 78-79)

TEXTO 11: Necesidad del dolor. Está en la constitución del hombre.

"¿Concebiréis que un ser pueda gozar de alguna felicidad verdadera fuera de su constitución? ¿No es sacar de ella a un hombre el querer exceptuarle Igualmente de todos los males de su especie? (Emilio II, p. 133>

Además del dolor, la resistencia, cuando se siente como necesaria, no irrita, no impacienta; es aceptada.

Texto 12: Sentimiento de la necesidad. Producto del apaciguamiento.

“...es natural en el hombre sufrir con paciencia la necesidad de las cosas, pero no la mala voluntad ajena. Las palabras "no hay más" son una respuesta que nunca irritó a un niño, a no ser que sospechase que era mentira. (Emilio II, p. 139)

Lo que está en el punto de partida de la idea. Lo necesario es fundado. Lo fundado no puede ser malo. Lo mismo ocurre con la necesidad de la muerte (textos de las pp. 125 y 126). Sentimiento oscuro, poco racional de la legitimidad de lo que es necesario.

VII. Aspecto poco conocido de la doctrina de Rousseau. Lo que vemos de ordinario en ella. Otro sentimiento, otro principio. Cómo se concilian. La verdadera libertad: hacer lo que se pueda. Lo que implica la sensación de lo imposible.

Queda por lo tanto claro que se trata de otra libertad. Libertad contenida, limitada. La noción de limitación le es esencial Disciplina severa. Error sobre Rousseau.

\section{B) ¿COMO DAR ESTE SENTIMIENTO? ¿POR LOS HOMBRES?}

I. ¿Qué fuerzas oponer? ¿La voluntad de los hombres? ¿El mandato? ¿La obediencia? Entonces, nada de necesidad. Voluntad arbitraria por lo tanto. Mandato = reclamar el acto porque se lo ordena, no porque es necesario. Lo que es deseado puede no ser deseado. Contingencia. Tan pronto como el niño se siente al frente de una voluntad semejante, puede triunfar. Medio de plegarse.

II. Además, ¿a nombre de qué imponer las voluntades? En nombre de la opinión. Ahora bien, la opinión no expresa las cosas como son. Las desnaturaliza. Son cosa artificial, muerte, enfermedad.

TEXTO 13: La opinión

"Separad la fuerza, la salud, y el buen testimonio de sí propio; todos los demás bienes de esta vida consisten en la opinión; sí hacéis caso omiso de los dolores del 
cuerpo y de los remordimientos de conciencia, todos nuestros males son Imaginarios". (Emilio II, p. 124>.

TEXTO 14: El origen del mal.

'Todos nuestros males morales están en la opinión”. (Emilio II, p.126)

(Lo mismo la enfermedad. Creencia de que es una enfermedad la que produce nuestro tormento. Con mayor razón para la muerte)

"Vive según la naturaleza, sé sufrido y despide a los médicos, no evitarás la muerte, pero no la sentirás más que una vez, en tanto que ellos la llevan cada día a tu turbada imaginación, etc..." (Emilio II, p. 126>

III. Existen sin embargo los preceptos de la moral. Pero el niño no tiene idea de ellos. ¿Por qué? Estos son conocidos por la razón, pero la razón no existe en el niño.

TEXTO 15: Moralidad y razón.

"La razón por sí sola nos enseña a conocer el bien y el mal. La conciencia que nos hace amar a uno y aborrecer a otro, aunque Independiente de la razón, no se puede desenvolver sin ella. Antes de la edad en que se posee el uso de la razón, obramos bien o mal ignorando si lo que hacemos es una cosa buena o mala; por consiguiente, no hay moralidad en nuestras acciones, aunque algunas veces la haya en la impresión que en nosotros hacen las acciones de otros relativas a nosotros". (Emilio 1, p. 106)

Poner el arado delante de los bueyes.

TEXTO 16: La razón para el final.

"La obra maestra de una buena educación es formar a un hombre racional, iy se pretende educar a un niño por la razón! Eso es comenzar por el final, y querer hacer del Instrumento la obra. Si los niños escuchasen la razón, no habría necesidad de que fueran alumnos". (Emilio II, p. 136)

El niño es moralmente neutro. Entonces no comprenden la razón de las órdenes. No se podrán someter por su entera voluntad. Obediencia exterior (textos de las pp.136 y 137). Ideas falsas.

IV. Nada de órdenes en el sentido propio de la palabra. Nada de invocar la autoridad. Por consiguiente, proscripción de los móviles ordinarios. La disciplina en la emulación. Todo esto es artificial.

TEXTO 18: Proscripción de los móviles ordinarios (emulación, temor)

"Muy extraño es que desde que se dedican los hombres a la educación de los niños, no hayan imaginado otra forma para conducirlos que la emulación, los celos, la envidia, la vanidad, el ansia, el miedo, las pasiones más peligrosas ...las más capaces de corromper el alma". (Emilio II, p. 139). 


\section{C) LAS COSAS ${ }^{8}$}

1. Solas, las cosas pueden dar el sentimiento de necesidad. Porque solas, se someten a las leyes necesarias. Aquí, nada de arbitrariedad. Ellas son lo que son. (Texto) ${ }^{9}$

Aquí, más de voluntad caprichosa. Lo posible y lo imposible (texto) ${ }^{10}$ La fuerza de las cosas.

II. Las cosas conocidas por sensaciones. El alumno en un medio puramente sensible. De acuerdo con su naturaleza, el niño no tiene más que sensaciones.(Texto $)^{11}$.

III. Gran novedad. Principio de la educación hasta entonces. Los hombres. Se forma el hombre por el hombre.

Principio invertido. La formación por las cosas. Las cosas introducidas hasta el momento están fuera del mundo moral. Tienen todavía un sentido. Sin embargo, contribuyen a preparar al hombre moral. Propedéutica esencial. El sentimiento indispensable viene de allá. Para ser iniciado en el mundo moral. El sentimiento moral no viene de la naturaleza.

¿Por qué? El hombre moral es pariente de la naturaleza.

TERCERA LECCION: forma definitiva

\section{A) LA DEPENDENCIA DE LAS COSAS}

1. Aspecto poco conocido de la doctrina. Liberalismo. Necesidad de una disciplina, de una contención. Nada de infinito. Limitación. Deseos limitados. Equilibrio.

II. ¿Pero, para qué? ¿Voluntad? Contingencias. Dependencia contre nature. ¿Por qué una voluntad ante una voluntad?

Espectáculo de la naturaleza. Todo lo que se acaba se detiene. No puede hacer otra cosa. Ninguna elección: leyes inflexibles.

\section{Retorno a El contrato social ${ }^{12}$}

IV. Nada de orden; nada de obediencia.

TEXTO 1: Nada de obediencia.

"Que él no sepa, cuando obra, qué es obediencia, ni qué cosa es imperio cuando se trabaja por él". (Emilio II, p.131)

\footnotetext{
${ }^{8}$ Este tema se encuentra mejor desarrollado en la redacción definitiva de la tercera lección (ver el parágrafo: "La dependencia de las cosas").

${ }^{9}$ Falta el texto indicado, pero es evidente que se trata del texto 6 de la lección siguiente (Emilio II p 139-140).

${ }^{10}$ Falta el texto, pero es evidente que se trata Igualmente de las pp. 139 y 140.

${ }^{11}$ Falta el texto indicado, pero es evidente que se trata de Emilio II, pp. 136 y 140.

${ }^{12}$ Ver Revue de métaphysique et de morale, tomo 25, p. 21 (Reproducido en Émíle Durkheim, Montesquieu et Rousseau (Paris: Libraírie Marcel Rivíére et Cje, 1953).
} 
Nada de lecciones verbales.

TEXTO 2: Nada de lecciones.

"No deis a vuestros alumnos lecciones verbales de ninguna clase, puesto que sólo deben recibirlas de la experiencia". (Emilio II, p. 140)

Nada de acción del niño sobre el maestro.

TEXTO 3: Ni obediencia ni mandato. Necesidad.

"Nada debe conseguir vuestro hijo porque lo pida, sino porque lo necesite, y que no debe hacer nada por obediencia sino por necesidad; de forma que las voces obedecer y mandar se proscriben de su léxico, y más aún las de obligación y deber, pero las de fuerza, necesidad, impotencia y precisión deben ocupar un destacado lugar". (Emilio II, pp. 135-136).

Entonces, nada de castigos.

TEXTO 4: Nada de castigos.

“...jamás se debe castigar a los niños como tal castigo, sino que el castigo siempre les debe venir como consecuencia de una mala acción". (Emilio II, p. 152) (Aplicación a la Mentira)

Además, nada de moralidad.

\section{TEXTO 5:}

"Careciendo de moralidad en sus acciones, no pueden realizar ningún acto Inmoral ni que sea merecedor de represión o de castigo". (Emilio II, p. 140).

V. ¿Dónde buscar entonces la fuerza que frena y contiene? En las cosas. Actúan necesariamente; impersonalmente. No obedecen a ninguna voluntad personal. Es pues de ellas solas que debe emanar esta primera educación. La fuerza de las cosas.

Sentido de lo posible y de lo imposible.

TEXTO 6: La fuerza de las cosas.

"No conviene que se encargue de educar un niño quien no lo sepa conducir a donde quiera por las solas leyes de lo posible y lo imposible". (Emilio II, p. 139-140)

Límites naturales de las cosas. Sentido de la necesidad.

TEXTO 7: Fuerza, no autoridad.

“...que sienta pronto sobre su cabeza altiva el duro yugo que la naturaleza impone al hombre, el pesado yugo de la necesidad, bajo el cual es necesario que todo ser se 
rinda; que vea esta necesidad en las cosas, pero nunca en el capricho de los hombres; que el freno que le retenga sea la fuerza y no la autoridad". (Emilio II, pp. 138-139)

\section{Obstáculos psíquicos.}

TEXTO 8: La dependencia de las cosas.

"Mantened al niño dentro de la sola dependencia de las cosas, y habréis seguido el orden de la naturaleza en el progreso de su educación. No ofrezcáis jamás a sus voluntades indiscretas más que obstáculos físicos ni castigos que no nazcan de las mismas acciones, y que se le recuerde cuando se presente la ocasión; sin defenderle de su mal hacer, es suficiente con estorbárselo. La experiencia o la Impotencia por sí sotas deben mantenerlo en el lugar de la ley". (Emilio II, p. 131)

\section{VI.Nada de castigos como tales.}

TEXTO 9: Nada de castigos.

“...tampoco le debéis Imponer ningún castigo, ya que Ignora lo que puede significar culpabilidad; ni le obliguéis a pedir perdón, puesto que no tienen el poder indispensable para ofenderos. Careciendo de moralidad en sus acciones no pueden realizar ningún acto moral ni que sea merecedor de represión o de castigo". (Emilio II, p. 140)

Lo que esto significa. El freno es aceptado porque surge de la naturaleza de las cosas. ¿Por qué reemplazarlas? Consecuencias psíquicas del acto. Método de las consecuencias naturales.

VII. Autoridad negada en esta primera educación. Carácter sui generis que impone el respeto y la obediencia. Actuar por respeto a la autoridad. Idea explícitamente negada por Rousseau.

¿De toda educación? ¿De toda la vida social y moral? No. Se trata de la primera. La autoridad vendrá después. Autoridad de la ley. Pero deberá estar modelada por esta acción de las cosas, es decir, sobre la necesidad psíquica. Necesidad, forma primera de obligación.

Necesidad de este orden para que el sentimiento de autoridad sea normal.

VIII. Comparación con Spencer. Este niega toda disciplina, toda contención. Sentido de lo útil y de lo perjudicial. Nada de coacción. Se dirige al interés.

Rousseau siente la disciplina como indispensable. Sentimiento vivo, siempre presente. Contención. Esfuerzo sobre sí mismo. Clase de moralidad.

Es discutible que la moralidad pueda formarse de esta manera. El sentido de la moralidad y de la autoridad. Igualmente el carácter de generalidad y de impersonalidad verdaderas de la autoridad moral. La regla. Kant y Rousseau. Pero el carácter imperativo no es menos necesario. Mandato impersonal.

\section{B) RELACIONES ENTRE EL MAESTRO Y EL ALUMNO}


I. Luego, el niño deberá vivir en un ambiente de cosas. Es por consiguiente sensible. Está además de acuerdo con su naturaleza de niño. El hombre en estado de naturaleza.

TEXTO 10: Medio sensible.

"Haced que, mientras sólo le muevan las cosas sencillas, todas sus ideas se paren en las sensaciones, haced que por todas partes sólo el mundo físico distinga alrededor suyo; de lo contrario, estad seguros que no os escuchará, o que se hará del mundo moral de que le habláis nociones fantásticas que no podréis borrar en adelante". (Emilio II, p. 136)

II. ¿Pero entonces, nada de maestro? ¿Nada de acción? Error de interpretación. Nada de acción directa. Pero toda acción no está prohibida. El maestro dispone de las cosas; está detrás de ellas; las ordena legítimamente.

Posee una fuerza considerable. El maestro puede imponerse no por medio de órdenes, sino tratando de dirigir las cosas.

TEXTO 11: El maestro y las cosas.

"Que cree que él (el alumno) es siempre el dueño, pero debéis serlo vosotros de verdad. No hay ninguna sujeción más completa como la que posee todas las apariencias de libertad, ya que de este modo está cautiva la voluntad misma. ¿No está a vuestra disposición un pobre niño que nada sabe, que lo ignora todo? ¿No sois vosotros los que disponéis de todo lo que tiene relación con él y de todo lo que está cerca de él? ¿No están en vuestra mano, sin que él lo sepa? ... No hay duda de que no debe hacer otra cosa que lo que él quiera, pero sólo lo que admitís que haga, pues no debe dar un paso sin que vosotros lo tengáis previsto, ni desplegar los labios sin que sepáis lo que va a decir". (Emilio II, pp. 180-181).

Según lo anterior, se puede hacer todo lo que se quiera.

TEXTO 12: Poder del maestro por la fuerza de las cosas. (Lo importante es dar la impresión de la fuerza de las cosas)

"La esfera del uno y del otro [de lo posible y de lo imposible] son para él Igualmente desconocidas, y se ensancha o se estrecha a su alrededor como uno quiere. Solamente con el vínculo de la necesidad, sin que él exprese la menor queja, se le encadena, se le empuja o se le contiene; sólo con la fuerza de las cosas se le transforma en dócil y manejable, sin permitir que le penetre ninguna clase de germen". (Emilio II, p. 140)

III. Por esto se explican las pretendidas contradicciones. La comedia de los vidrios rotos. En realidad no hay contradicción. Hacer sentir la fuerza de las cosas, presentarlas en el orden adecuado para que ellas produzcan la acción que hay en ellas, no viola el principio. Son las cosas las que actúan. Es su lección la que forma.

IV. ¿Pero dónde encontrar un medio apropiado? Es difícil.

TEXTO 13: El teatro de la primera educación. (Entonces el placer está en el aislamiento) 
"Pero, ¿dónde debemos colocar a este niño para educarle de este modo, como un ser insensible, como un autómata? ¿le colocaremos en la Luna o en una Isla desierta? ¿Le apartaremos de todos los humanos?...

Yo conozco estas dificultades, las confieso y quizá sean insuperables, pero siempre es verdad que, dedicándose a evitarlas, tienen un límite remediable. Yo marco la meta hacía donde debe dirigirse la carrera; no afirmo que se pueda llegar a ella, pero aseguro que el que se acerque más al final, es el que mayores ventajas sacará". (Emilio II, pp. 143-144)

La aldea. Nada de sociedad.

Escenario de la educación:

"No podéis ser el árbitro del niño, si antes no lo sois de todo lo que le circunda". (Emilio II, p. 144)

\section{Escenario de la educación:}

"En un pueblecito el ayo será mucho más dueño de los objetos que quiera poner delante del niño; su prestigio, sus palabras, su ejemplo, tendrán una autoridad que no pueden tener en la ciudad, debido a que sirve útilmente a todos, y también anhelan complacerle, procuran granjearse su cariño y se presentan delante del alumno como desea el maestro". (Emilio II, p.145)

V. Sin embargo, este principio no puede ser absoluto. El niño interroga al maestro. El maestro responde. Relaciones inevitables. ¿Cómo deberían ser?

VI. El mismo principio. Que no hable el maestro; que la cosa hable por sí misma. El alumno no debe ser escuchado; naturaleza de las cosas. No ceder porque él lo quiere; sino porque el deseo está fundado en la naturaleza de las cosas. Exigir condescendencia. Exigencia de las necesidades.

\section{TEXTO 14:}

(Es la necesidad, es decir, la naturaleza de las cosas la que debe dictar la conducta del educador)

"No complazcáis sus deseos porque lo pida, sino porque lo necesita. Que él no sepa cuando obra, qué es obediencia, ni qué cosa es imperio cuando se trabaja por él; que sienta por igual su libertad en sus acciones y en las vuestras". (Emilio II, p. 131)

Y como son las cosas las que hablan, el maestro debe expresarse como las cosas. Las manifestaciones de su voluntad deben tener carácter de manifestaciones naturales. Necesidad.

Eficacia del vínculo de necesidad:

"Solamente con el vínculo de la necesidad, sin que él exprese la menor queja, se le encadena, se le empuja o se le contiene; sólo con la fuerza de las cosas se le 
transforma en dócil y manejable, sin permitir que le penetre ninguna clase de germen". (Emilio II, p. 140)

Irrevocabilidad

No ceder a los llantos, pero si a la necesidad.

"Si la necesidad es la causa que ha hecho que el niño hable, debéis conocerlo, y hacer al instante lo que pida, pero ceder a sus lágrimas, es excitarle a que las vierta, es enseñarle a que dude de vuestra voluntad y a creer que el insistir pueda ser más efecto sobre vosotros que vuestra misma benevolencia". (Emilio II, p. 132)

\section{Muro de bronce.}

TEXTO 15: Voluntad, muro de bronce.

"No le prohibáis las cosas de que deba abstenerse; evitad que las haga, sin explicación ni raciocinio; lo que le concedáis, concedédselo a la primera palabra que diga, sin Inquirir, sin ruegos, y sobre todo sin condiciones ... pero que todas vuestras repulsas sean irrevocables; no os doblegue importunidad alguna; que el nó que se pronuncie sea un muro de bronce, contra el cual, apenas haya probado el niño cinco o seis veces sus fuerzas, ya no Intentará abatirlo". (Emilio II, p. 139).

VII.- Gran novedad. Hasta el presente, la educación ha sido del hombre por el hombre. Exclusión de la naturaleza. Lo material y lo espiritual.

Principio invertido. Las cosas. En cierto sentido tienen todavía su carácter antiguo. No hay dominio de la moralidad. Más prepárense para la formación moral. Propedéutica esencial. El sentimiento indispensable viene de ellas (disciplina, moderación). Deberá modificarse, tomar una nueva forma. Pero para transformarse, debe ser. No puede formarse más que en la escuela de las cosas.

¿Por qué? El hombre civil a imagen del hombre natural.

\section{C) LA EDUCACION NEGATIVA}

I. ¿Cómo calificar esta educación? ¿Negativa? Así se la ha llamado. Rousseau mismo se ha servido de la expresión. ¿Por qué? ${ }^{13}$

II. Por lo general es la que niega la acción del hombre. De allí la negación de la moral.

III. Sin embargo, la moral negativa tiene un valor positivo.

TERCERA LECCION: primer borrador (no definitivo)

\section{a) LA DEPENDENCIA DE LAS COSAS}

I. Recuerdo del principio. Es necesario que el hombre se sienta contenido, sujetado. Le es necesario un freno. ¿Por qué? El equilibrio como condición de la felicidad. ¿Pero, por

\footnotetext{
${ }^{13}$ No reproducimos los textos dado que son los mismos de la sección a) de la cuarta lección (forma definitiva).
} 
quién? ¿Por voluntades humanas? Fuerzas psíquicas. Para que las resistencias sean aceptadas, se requiere que sean sentidas como necesarias. Legítimas, porque están fudadas en la naturaleza de las cosas. La fuerza de las cosas expresa su naturaleza.

Las voluntades humanas debieran ser descartadas. Son contingentes. O ellas no hacen más que solicitar lo que reclaman las cosas, y son inútiles. O ellas se suman a las cosas y las alteran. Superponen al mundo real, un mundo de ficciones, de imaginaciones. La opinión, ¿es la moral?

II. Quedan entonces las cosas. Ellas solas pueden provocar el sentimiento de necesidad. Son sumisas a las leyes necesarias. Inflexibles. Nada de arbitrariedad: son lo que son. Su acción se desprende de su naturaleza. (Texto) ${ }^{14}$

Lo que lo frena es el sentimiento de lo imposible. (Texto). Y esta contención es aceptada. Es fuente de una disciplina espontánea. (Texto).

III. Nada de órdenes. Nada de mandatos. Nada de obediencia. (Texto). En general, nada de lecciones verbales. Cosas elocuentes. (Texto).

Por lo tanto, nada de penas en cuanto tales. Sólo lo que ellas son. No hay lugar para ellas. 1) Nada de orden, y 2) nada de moralidad. Ellas deben ser reemplazadas por las consecuencias naturales del acto. (Texto).

IV. Es la idea de autoridad la que se niega. Definir la idea. Carácter sui géneris que impone el respeto y la obediencia. Se debe obrar por respecto a una autoridad. Autoridad de la regla y de la persona.

Rousseau hace explícito esta consecuencia de su doctrina (Texto).

V. Pero las cosas no son conocidas sino por la sensación. Entonces, el niño debe vivir en un medio puramente sensible, conforme a su naturaleza. No está maduro para el mundo moral. (Texto).

\section{b) EL PAPEL DEL MAESTRO Y SUS RELACIONES CON EL ALUMNO}

I. ¿Por lo tanto, nada de maestro o de testigos? No. Lo que se ha defendido es la acción directa. No toda acción. El maestro debe disponer de las cosas. Está detrás de ellas. Posee una fuerza considerable. (TEXTO).

Es allí donde se explican las aparentes contradicciones. La comedia del jardinero; los vidrios rotos.

II. Esta misma razón es la que determina cuál debe ser el escenario de esta primera educación. Problema difícil. (Texto). Es la aldea, el campo. ¿Por qué? (Texto).

III. Rousseau siente, sin embargo, que el principio no puede ser absoluto. El niño pregunta al maestro. El maestro responde. Las relaciones directas son inevitables. ¿Cuáles son ellas?

\footnotetext{
${ }^{14}$ Los textos se encuentran en la redacción anterior de la misma lección
} 
IV. Reglas según el mismo principio. Las cosas harían de intermediario entre el alumno y el maestro. Ahora el maestro expresa cosas. No es el maestro quien debe hablar; son las cosas por su boca. No es el alumno quien debe ser escuchado; es la naturaleza de las cosas. No ceder o resistir porque el niño lo desea o porque lo solicita. Sino porque las cosas imponen la condescendencia. Necesidad. (Textos).

Y como es la naturaleza la que habla, es necesario que las manifestaciones de la voluntad del maestro tengan todo el carácter de manifestaciones naturales. Necesarias. Irrevocables. Muro de bronce. (Textos).

\section{Siempre el mismo principio. El Contrato Social}

V. Gran novedad. Hasta el presente, instrumento único de la educación: el hombre. Se forma el hombre por el hombre. Desarrollar. Nada de naturaleza.

Principio invertido. Las cosas. Hasta aquí puestas fuera del mundo moral. Oposición de lo espiritual y de lo material. En un sentido las cosas tienen todavía este carácter. No poseen moralidad, pero preparan a hacer el hombre moral. Propedéutica esencial. El sentimiento indispensable viene de él. Sentimientos de disciplina, de equilibrio, de orden moral.

Importancia del estado de naturaleza en el mundo moral. ¿Cómo es posible? Es que el hombre moral es pariente del hombre en el estado de naturaleza. Aquél es el modelo.

\section{c) CONCEPCION DE LA EDUCACION NEGATIVA}

I. ¿Esta educación es negativa? Rousseau se sirve de esta expresión. (Textos) ${ }^{15}$

II. Ello es verdad en cierto sentido. Exclusión del hombre y de la sociedad. Ni las opiniones. (Texto). Ni la moral. Moral completamente negativa.

III. Pero esta moral negativa tiene un valor positivo. Es la parte esencial de la moral. ¿Por qué? Explicación. Estado de inocencia. Moral negativa. Luego debe ser también la virtud par excellence. Concepción de la vida social: los individuos no sc hacen daño, no se desbordan. Nada de fusión, nada de comunión.

Forma de votar.

IV. Generalmente, la acción de las cosas tiene un efecto positivo. Ella forma. Constituye la parte principal de la educación. (Texto). ¿Por qué? El hombre en el estado natural es la base del hombre moral y civil; todo depende de los fundamentos. El uno reproduce al otro. Regreso sobre las dos educaciones. De donde gran importancia de la primera educación y de la primera edad. (Texto).

V. Todo lo anterior contiene lo esencial de la doctrina. El resto es menos original y profundo. Seremos más breves.

CUARTA LECCION: forma definitiva

${ }^{15}$ Los textos se encuentran en su forma definitiva en la cuarta lección (secciones a) y b)). 


\section{A) CONCEPCION DE LA EDUCACION NEGATIVA}

I. Resumen de lo anterior. Se trata de la primera educación. El maestro, estas son las cosas. De ellas se desprende la acción educativa. Desaparición del maestro.

II. ¿Cómo calificarla? Es positiva si transmite ideas y sentimientos. Aquí ninguna. El maestro se abstiene. Permanece a distancia. Nada de acción informativa. Por lo tanto negativa.

TEXTO 1: La Educación negativa.

"La primera educación debe ser puramente negativa. [¿Por qué?] Ella no consiste en enseñar ni la virtud ni la verdad, sino en librar de vicios el corazón y el espíritu del error. SI pudierais no hacer nada, sí lograrais tener sano y robusto a vuestro alumno hasta la edad de doce años, sin que supiera distinguir su mano derecha de la izquierda, desde vuestras primeras lecciones se abrirían los ojos de su entendimiento". (Emilio II, p. 142)

\section{TEXTO 2 : Espectativa.}

"Para formar este hombre raro, ¿qué tenemos que hacer nosotros? Mucho, sin duda. Se ha de evitar lo que se ha hecho. Cuando sólo se trata de navegar contra el viento, se bordea, pero si esta alborotado el mar y se quiere permanecer en el sitio, es preciso echar el ancla". (Emilio 1, p. 71)

III.Expresión verdadera en cierto sentido. Alguna cosa ha de eliminarse, negarse; hombre. Sociedad. Nada de informaciones. Las opiniones son eliminidas.

TEXTO 3: Educación negativa.

(Se trata de) "librar del choque de las opiniones humanas al naciente arbolillo". (Emilio 1, p. 65)

Carácter negativo muy acusado en lo que concierne a la moral.

TEXTO 4: El niño debe permanecer extraño al mundo de la moral -este es el vicio introducido- pues no debe conocer más que el mundo físico.

"Antes de la edad de la razón, no es posible tener ninguna idea de los seres morales, ni de las relaciones sociales; por tanto se ha de evitar, hasta donde sea posible, el uso de las voces que las expresan, por temor a que el niño aplique Inmediatamente a esas palabras ideas falsas, que luego no sabremos o no nos será posible destruir. La primera Idea falsa que entra en su cabeza es el germen del error y del vicio, por lo que es necesario poner mucha atención ante este primer paso. Haced que, mientras sólo le muevan las cosas sencillas, todas sus ideas se paren en las sensaciones; haced que por todas partes sólo el mundo físico distinga alrededor suyo, de lo contrario, estad seguros de que no os escuchará, o que se hará del mundo moral de que le habláis nociones fantásticas que no podréis borrar en adelante". (Emilio II, p. 136).

(Comparación con Descartes). 
IV. Pero ante todo, moral negativa de valor positivo. Parte esencial de la moral.

TEXTO 5: importancia de la moral negativa.

"La sola lección de moral que conviene a la infancia ... es la de no causar ningún mal a nadie. El mismo precepto de hacer el bien, cuando no está subordinado al otro, es peligroso, falso y contradictorio. ¿Quién hay que no haga el bien? Todo el mundo hace algo bueno, lo mismo el perverso como los otros, el cual hace un hombre dichoso a costa de cien miserables, y de aquí vienen todas nuestras calamidades. Las más sublimes virtudes son negativas, y son también las más difíciles, porque van desprovistas de ostentación y ocupan un lugar más elevado que el mismo placer, tan dulce para el corazón del hombre, deseoso de que otro se vaya contento y satisfecho de nosotros". (Emilio II, pp. 157-158)

¿Por qué? El hombre en estado de naturaleza vive en la inocencia. Es lo mismo que en el estado de aislamiento $^{16}$ No hay sociedad ni maldad. Por lo tanto, moral par excellence.

Llevar este punto de vista dentro del estado social: hombres no lastimados; no desbordados; respetando los límites. El Contrato social. Nada de fusión ni de comunión. Relaciones todas negativas.

La forma de $\operatorname{votar}^{17}$

V. Esta moral es positiva en otro sentido. La acción de las cosas. Ella es positiva. Forma. Imprime en el espíritu actitudes definidas que se encuentran por todas partes, y son la base de todo. Son parte esencial de toda educación. Base de toda constitución moral e intelectual.

TEXTO 6: Importancia de la educación espontánea.

“...la educación del hombre empieza al nacer; antes de hablar, de comprender, él ya se instruye. La experiencia precede a las lecciones; cuando conoce a su nodriza, tiene ya mucho adquirido. Uno se sorprendería del hombre, el más rústico, si siguiéramos sus progresos desde el momento en que nació hasta aquel en que se halla. Si se dividiese toda la ciencia humana en dos partes, la una común a todos los hombres y la otra propia de los sabios, la última sería muy pequeña comparada con la primera".(Emilio I, p. 99)

El hombre en el estado civil se basa en el hombre natural y todo depende de sus fundamentos. Uno está modelado sobre el otro. Es de allí de donde nosotros extraemos el sentido de lo real.

VI. Importancia de la primera educación. Esta es una edad crítica. Error o verdad.

TEXTO 7: La primera edad, edad crítica.

"El más peligroso tiempo de la vida humana es el que va desde el nacimiento hasta la edad de doce años, debido a que es cuando brotan los errores y los vicios, sin que haya aún ningún instrumento capaz de destruirlos, y cuando éste se obtiene, la raíces

\footnotetext{
${ }^{16}$ Alusión a Robinson Crusoe.

${ }^{17}$ Alusión al voto del pueblo soberano y a la expresión de la voluntad general. 
están tan profundas que ha pasado el tiempo propicio para arrancarlas". (Emilio II, p. 142)

Importancia cartesiana de las nociones iniciales.

VII. Insistir sobre el papel atribuido a las cosas. No interpretar a Rousseau con fórmulas corrientes. La idea puede ser paradojal, pero original.

Las cosas aconsejan porque hablan a la imaginación, golpean, son fácil y enérgicamente percibidas. Medios de escapar a la abstracción. Instrumentos cómodos, complementarios.

Para Rousseau todo esto es verdad. Pero hay una razón más profunda. Las cosas son instrumentos de cultura. No proceder mediante auxilios. La acción moral no puede venir de ellos. Las cosas hacen al hombre.

Extraer el sentido profundo. Ley moral, muro de bronce que frena. Yugo saludable. Inmoralidad, por voluntad caprichosa. El contacto con la naturaleza puede ayudar. Igualmente las ciencias sirven a la formación moral. Sentido de la necesidad, de la resistencia de las cosas. Superioridad de las voluntades. Es de esta educación premoral de la que se trata.

\section{B) APLICACION DEL PRINCIPIO A LA VIDA MORAL}

I. Si somos rigurosos, nada de educación moral. Nada de relaciones humanas; por lo tanto nada de moralidad. Si nos sentimos obligados a darle ideas morales, es porque nos desviamos de la regla; es porque incluimos al hombre entre las cosas y los niños. Mala introducción.

Ejemplo: la mentira. 1) Relativo al pasado. El niño tiene todo el interés en decir lo que es, dado que tiene necesidad de los otros para adaptarse. Engañar hacerse daño. Miente porque nosotros se lo hemos mandado. 2) Prometer aquello que no tenemos la intención de sostener. Pero el niño ignora la convención social. No existe más que en el presente.

TEXTO 8: La mentira.

'De esto se deduce que las mentiras de los niños son la obra de los maestros, y querer que así aprendan a decir la verdad no es más que enseñarles a mentir". (Emilio II, p. 154)

II. Sin embargo todo esto es prácticamente imposible. Contacto con los hombres; no hay vacío absoluto. Nociones necesarias. Pero 1) tardías; 2) sensibles. El presente.

TEXTO 9: Necesidad de una iniciación moral.

"Yo tengo por imposible que en el seno de la sociedad pueda llegar un niño a los doce años sin que se le den algunas Ideas de las relaciones que existen de hombre a hombre y de la moralidad de los actos humanos. Es suficiente tener un gran cuidado de que no precise estas nociones hasta lo más tarde posible, y cuando ya sean inevitables, que queden limitadas a la utilidad del momento, solo con el fin de que no se considere el dueño de todo ni perjudique al prójimo sin ningún escrúpulo o por 
ignorancia ... pero también los hay de naturaleza violenta cuya irascibilidad se manifiesta muy pronto, y es forzoso darse prisa en hacerlos hombres para no hallarnos en la obligación de tenerlos encadenados". (Emilio II, p. 147)

¿Va Rousseau a violar este principio? No. No hay mandatos ni defensas. La enseñanza debe venir de la realidad, de la consideración de fuerzas que están en juego. El maestro se limitará a dirigirlas y manejarlas. Acción del educador comparada con la del médico.

III. De todos modos el maestro debe ocultar su acción para que el alumno no la sienta. De otra manera, el efecto se malogrará. Producto de las voluntades y no de las cosas. Su actuación es entonces necesaria.

IV. ¿Cómo hacerlo? Dos aspectos de la vida moral. Derechos y deberes. Es por los derechos que debemos comenzar. Solo hay sentimiento en el niño: amor de sí mismo. Es de este móvil que hay necesidad de servirse.

TEXTO 10: Deberes y derechos.

Todos nuestros movimientos naturales se refieren primero a nuestra conservación y a nuestro bienestar. Así, el primer sentimiento de la justicia no nos viene de la que nosotros somos deudores, sino de ja que nos deben; por ese motivo, hablar siempre de las obligaciones a los niños y nunca de sus derechos, comenzando por decirles lo contrario de lo que necesitan, cosa que no les interesa, ni pueden entender, es uno de los defectos comunes de la educación". (Emilio II, p. 148)

V. ¿Pero cuáles derechos? ¿Personas? ¿Cosas? Las personas pueden defenderse. Reaccionar por ellas mismas. No amenazar.

De otra forma las cosas. "La primera Idea que se le debe sugerir es que es de menos Importancia la de libertad que la de propiedad" (Emilio II, p. 148).

\section{¿Por qué? Artificial.}

VI. ¿Entonces, su derecho de propiedad? ¿Cómo? Lecciones de cosas. Hacerlo asistir a la génesis de su derecho: darle la sensación. Proporcionar el conjunto de circunstancias de las cuales surgió esta institución.

Exclusión de juguetes, vestidos. Pues la propiedad no es primitiva.

VII. Lo que este derecho implica originalmente. 1) El trabajo. 2) El derecho del primer ocupante. "La idea de propiedad es natural al derecho del primer ocupante por el trabajo" (Emilio II, p. 150). Dos elementos. 1) Trabajo. 2) Privilegio del primer ocupante por la fuerza.

VIII. De allí pasar al respeto de la propiedad del prójimo. El contrato. Los vidrios rotos. El niño encerrado. Acuerdo. Compromiso. Primera obligación. Primer vínculo social. El individuo está atrapado.

TEXTO 11: El vínculo social. 
“...cuando hacía un agujero para sembrar unas habas, el pequeño rebelde no pensaba que existía un calabozo en el cual no tardaría mucho en encerrarle su ciencia.

Estamos aquí en el mundo moral y ved ahí la puerta abierta al vicio; con los pactos y las obligaciones nacen la mentira y el engaño ... Estas son las miserias de la vida humana, las cuales tienen sus inicios con los errores".(Emilio II p. 152)

\section{Detenerse aquí}

IX. Otro principio. La imitación. "El hombre es un ser que imita a los demás, lo mismo que los animales. La propensión a imitar sale de la naturaleza bien ordenada" (Emilio II, p. 157).

Procedimiento inferior; tanto más apropiado.

TEXTO 12: Imitación.

"Yo sé que las virtudes de imitación son como las de los monos ... Pero es necesario procurar que jos niños imiten jos actos cuyo hábito queremos que adquieran, puesto que a su edad todavía no siente nada su corazón, y mientras va llegando el tiempo del discernimiento, pueden realizarlos por amor al bien". (Emilio 11, p. 157)

Pero permanece fiel al principio. Exclusión de todo móvil social. Es el acto el que llama al acto. Nada de exhortación ni llamado al deseo de brillar.

CUARTA LECCION: primer borrador (no definitivo)

\section{a) CONCEPCION DE LA EDUCCION NEGATIVA}

I. Resumen: 1) imitación de la naturaleza. 2) Todo es limitado; condición de equilibrio. 3) ¿Limitación, para qué? Las cosas. Solas dan la impresión de límite necesario: invisible y legítimo.

Entonces el niño debe vivir en medio de las cosas. Ellas solas enseñan; y el maestro a través de ellas. Si trata por sí mismo, debe imitar la acción de las cosas fundándose en su naturaleza

II. ¿Pero entonces, como calificar esta educación?. Positiva, en la medida que implique la intervención dirigida a transmitir ideas, sentimientos, etc. El maestro se abstiene. Vigila a distancia. Nada de acción informativa. Por lo tanto negativa. (Texto) ${ }^{18}$

III. Expresión verdadera en un sentido: alguna cosa ha de eliminarse: el hombre, la sociedad. Negada. Opiniones humanas (Texto). Moral (Texto).

IV. Pero esta moral negativa tiene un valor positivo. Es la parte esencial de la moral. (Texto). ¿Por qué? El hombre en el estado de naturaleza vive en la inocencia. Es lo que

\footnotetext{
${ }^{18}$ Los textos se encuentran en la lección anterior, redacción de la misma lección.
} 
es. Los hombres lejos los unos de los otros. Nada de maldad. Moral negativa. Por lo tanto moral par excellence. Trasladar este punto de vista al estado social. Los hombres no se perjudican; no se desbordan. Nada de fusión; relaciones negativas.

Modo de votación.

V. Generalmente, la acción de las cosas es positiva. Educa. Imprime al espíritu actitudes definidas, que se encontraran por todas partes. Son parte esencial de toda educación. (Texto).

¿Por qué? La base del hombre civil es el hombre en estado de naturaleza, y todo depende de los fundamentos. Uno reproduce al otro. Regreso a las dos educaciones.

De donde se desprende la gran importancia de la primera educación. Es allí donde adquirimos el sentido de lo real. El hombre está hecho una vez que se lo ha terminado. Edad crítica. (Texto).

VI.Hay que insistir en el papel atribuido de esta manera a las cosas. No hay que interpretar a Rousseau con nuestras ideas y con nuestras fórmulas. Sus ideas pueden ser paradojales y falsas, pero son origínales. Las cosas aconsejan porque hablan a la imaginación, golpean y son percibidas con más fuerza y facilidad. Medios de escapar a la abstracción. Instrumentos cómodos, complementarios.

Para Rousseau instrumentos de la cultura. Sin duda, se comprende mejopr aquello que es sensible, pero hay enseñanzas que no pueden venir sino de las cosas y son esenciales. Hacen al hombre.

\section{b) APLICACION DEL PRINCIPIO A LA VIDA MORAL.}

I. Si uno se atiene al rigor del principio, nada de educación moral propiamente dicha. Nada de relaciones humanas. No hay lugar para la moralidad o la inmoralidad. Si uno se cree obligado a darle ideas morales, es porque nos apartamos de la regla, es porque introducimos al hombre entre las cosas y los niños. Lo introducimos torpemente.

Ejemplo. Mentira. 1) Relativo al pasado. El niño tiene todo el interés para decir lo que es porque tiene necesidad de los otros para adaptarse a las cosas. Engañar $=$ hacerse daño. Miente porque se le ha ordenado. 2) Prometer aquello que no tenemos deseo de cumplir. Pero el compromiso es una convención social. El niño no puede comprometerse: no existe sino en el presente.(Texto).

II. Sin embargo esto es prácticamente imposible. No existe un vacío absoluto.

El contacto con los hombres. Algunas ideas, o sensaciones morales necesarias.

(Texto).

¿Acaso Rousseau va a violar su principio? No. Obtener el resultado sin mandatos, ni defensas, ni castigos. La enseñanza debe venir de la realidad, de la vida, de las fuerzas en juego en la vida.

El maestro se limitará a manifestar y a dirigir. El arte del educador comparado con el arte del médico. 
No obstante, el maestro debe ocultar su acción, para que el alumno no la sienta y no tome la marcha de las cosas como producto de una voluntad arbitraria. De lo cual una comedia necesaria.

III. ¿Cómo tomarlo? Dos aspectos de la vida moral. Derechos y deberes. Es por los derechos que se debe comenzar. Solo hay sentimiento en el niño: amor de sí. Es dc él que es necesario servirse. Por lo tanto derechos. (Texto).

IV. ¿Pero qué derechos? ¿Derechos de las personas? ¿De las cosas? Aquello que amenaza ser lo más peligroso. Ahora bien, las personas pueden defenderse. Entonces, nada de amenazas. De lo contrario las cosas. "La primera idea que se le debe sugerir es que es de menos importancia la de libertad que la de propiedad." (Emilio II, p. 148).

Es por su derecho que hay que comenzar. ¿Pero cómo? Nada de enseñanza. Lecciones de cosas. Hacerle asistir a la génesis de su derecho: darle la sensación.(referirse al origen). Realizar artificialmente el conjunto de circunstancias que han originado el nacimiento a la institución de la propiedad.

Entonces exclusión de juguetes. Pues la propiedad es transmisible: no adquirida por él.

V. Lo que implica originalmente el derecho de propiedad: 1) El trabajo. 2) El derecho al primer ocupante. "La idea de la propiedad es natural al derecho del primer ocupante por el trabajo". Un pequeño drama en dos actos: 1) Trabajo. 2) Privilegio del primer ocupante. Resistencia de la fuerza.

VI. De allí pasar al respeto del prójimo. Contrato. Los vidrios rotos. Ellos son míos. Compromiso. Primera obligación. He aquí el vínculo social. El individuo está atrapado. (Texto).

\section{Detenerse.}

VII. Otro principio: La imitación. "El hombre es un ser que imita a los demás, lo mismo a que los animales. La propensión a imitar sale de la naturaleza bien ordenada". Procedimiento inferior. Tanto más apropiado.

Permanecer fiel al principio. Exclusión de todo móvil social. Es la observación del acto lo que suscita el acto. Nada de explicación ni del llamado al deseo de brillar o de hacerse aplaudir.

VIII. Lista no exhaustiva. El vicio. No hay desarrollo de las consecuencias. Hacerle sentir aquello que tiene de anormal. (Emilio II, pp. 146-147). 